\title{
Assessment of foetal cardiac function by myocardial tissue doppler in foetal growth restriction
}

\author{
Barnali Basu1*, Ranjan Shetty ${ }^{2}$, Krishnendu Gupta ${ }^{3}$
}

\begin{abstract}
${ }^{1}$ Department of Obstetrics and Gynecology, Kasturba Medical College, Manipal, Karnataka, India ${ }^{2}$ Department of Cardiology, Kasturba Medical College, Manipal, Karnataka, India

${ }^{3}$ Department of Obstetrics and Gynecology, Ramakrishna Mission Seva Prathishthan and Vivekananda Institute of Medical Sciences, Kolkata, West Bengal, India
\end{abstract}

Received: 31 January 2017

Accepted: 04 February 2017

\section{*Correspondence:}

Dr. Barnali Basu,

E-mail: barneybas@ hotmail.com

Copyright: (c) the author(s), publisher and licensee Medip Academy. This is an open-access article distributed under the terms of the Creative Commons Attribution Non-Commercial License, which permits unrestricted non-commercial use, distribution, and reproduction in any medium, provided the original work is properly cited.

\begin{abstract}
Background: One of the consequences of IUGR is the development of cardiac diastolic dysfunction in fetuses. Tissue doppler in echocardiography is a new technique to detect myocardial tissue function and can act as a useful tool in the identification of this complication. Hence we decided to undertake this study to assess the utility of myocardial tissue doppler in detecting foetal cardiac dysfunction in IUGR. It was a prospective case control study in a tertiary care teaching hospital.

Methods: Foetal cardiac function in the third trimester of pregnancy was evaluated with the help of myocardial tissue doppler and compared between IUGR and normal growth babies and correlated with vessel doppler findings and neonatal outcomes.

Results: There were sixty two IUGR and fifty eight normal growth babies in the study. In babies with IUGR, particularly the ones with severe IUGR, abnormal vessel doppler and adverse neonatal outcomes, right ventricular MPI was found to be significantly lower. However, the variable had a poor sensitivity (40\%) in detecting fetuses at risk for poor neonatal outcomes.

Conclusions: Myocardial tissue doppler shows right sided cardiac dysfunction in IUGR babies in comparison to normal growth babies It is however not a sensitive indicator of adverse perinatal outcome in IUGR babies.
\end{abstract}

Keywords: Cardiac dysfunction, IUGR, Myocardial tissue doppler

\section{INTRODUCTION}

Intrauterine growth restriction (IUGR) affects about 3-5\% foetuses in India. It mainly occurs due to uteroplacental insufficiency. If present for prolonged periods, the chronic hypoxia can lead to abnormal manifestations in various foetal organ systems with continued adaptive mechanisms that tend to get decompensated with time.

The foetal cardiovascular system is also not spared and several studies have proved the effect of the pathological process of placental dysfunction in IUGR on the foetal heart. ${ }^{1-5}$ Foetal cardiac function is complex and depends on myocardial contractility as well as on extra-cardiac factors such as developmental maturation, loading conditions and foetal disease. As the foetus is increasingly jeopardized, signs of cardiovascular dysfunction appear. Initially, there is decreased left ventricle afterload with cerebral vasodilatation and an increased right ventricle afterload due to systemic and pulmonary vasoconstriction to preferentially shift the cardiac output in favour of left ventricle to increase 
perfusion of the brain. With progressive prolonged hypoxia there is deterioration with impaired cardiac filling and drop in cardiac function.

Myocardial tissue doppler ultrasonography is a technique that allows measurement of myocardial velocimetry in systole and diastole without the limitations of conventional doppler which is influenced by cardiac rate and afterload conditions. As this technique involves assessment of tissue function, if used correctly it can provide us with valuable information regarding the functioning of foetal myocardium. As the cardiovascular changes in IUGR with progressive deterioration of intracardiac perfusion and consequent function tend to occur sometime before the signs of foetal distress appear on biophysical tests, the technique can detect cardiac dysfunction and may prove to be of valuable help in deciding on the management of foetuses with growth restriction. Studies done so far postulate that tissue Doppler could constitute a more sensitive tool than conventional vessel Doppler to predict cardiac dysfunction in foetuses with IUGR. ${ }^{6-8}$

\section{METHODS}

The study is a prospective observational study, carried out between August 2011 and August 2013, in a tertiary care hospital. Patients in the third trimester of pregnancy were taken for the study. Written and informed consent was obtained from all patients. They were divided into two groups:

- Study group comprising patients identified to be having IUGR with growth curve below the $10^{\text {th }}$ percentile.

- Control group comprising patients with foetal growth corresponding for their gestational age.

For every foetus taken in the IUGR group, a control was taken at the same gestational age. Exclusion criteria were patients with multiple gestation and foetuses with cardiac anomalies.
Foetal echocardiography was done along with myocardial tissue Doppler in all these patients with help of Vivid GE machine. Sampling was done at the level of the basal part of the left ventricular free wall, right ventricular wall and interventricular septum.

The variables of tissue doppler taken for all the three areas were: ${ }^{9}$

- E'- the mean peak value of three early diastolic waves

- $\mathrm{A}^{\prime}$ - the mean value of three late diastolic or atrial filling waves,

- E'/A'- The ratio between the two,

- Myocardial performance index (MPI') - Calculated by the formula ICT'+IRT'/ET' where: ICT' stands for iso-volumetric contraction time, ET' stands for ejection time and IRT' for isovolumetric relaxation time.

Conventional vessel doppler examination was also done for all of these patients. All patients were followed up to 7 days post-delivery. Adverse neonatal outcomes were taken as: NICU admission for $>5$ days, hypoglycemia, respiratory distress syndrome, presence of cardiomegaly, neonatal seizures and mortality. The variables obtained by myocardial tissue doppler were compared between the study and control group. Comparison was also made between babies with normal and abnormal vessel doppler and among babies with normal and adverse outcomes. Statistical analysis was done with the help of SPSS software 16.

\section{RESULTS}

Sixty two patients had IUGR and Fifty eight with growth appropriate for gestation (Figure 1). The babies with IUGR were classified on the basis of severity which was assessed based on the birth weight. This was done as:

- $\quad$ Severe IUGR- Birth weight $<1.5 \mathrm{~kg}$

- Moderate IUGR- Birth weight- $1.5-2 \mathrm{~kg}$

- $\quad$ Mild IUGR- Birth weight- 2-2.5 kg

Table 1: Demographic characteristics of the patients.

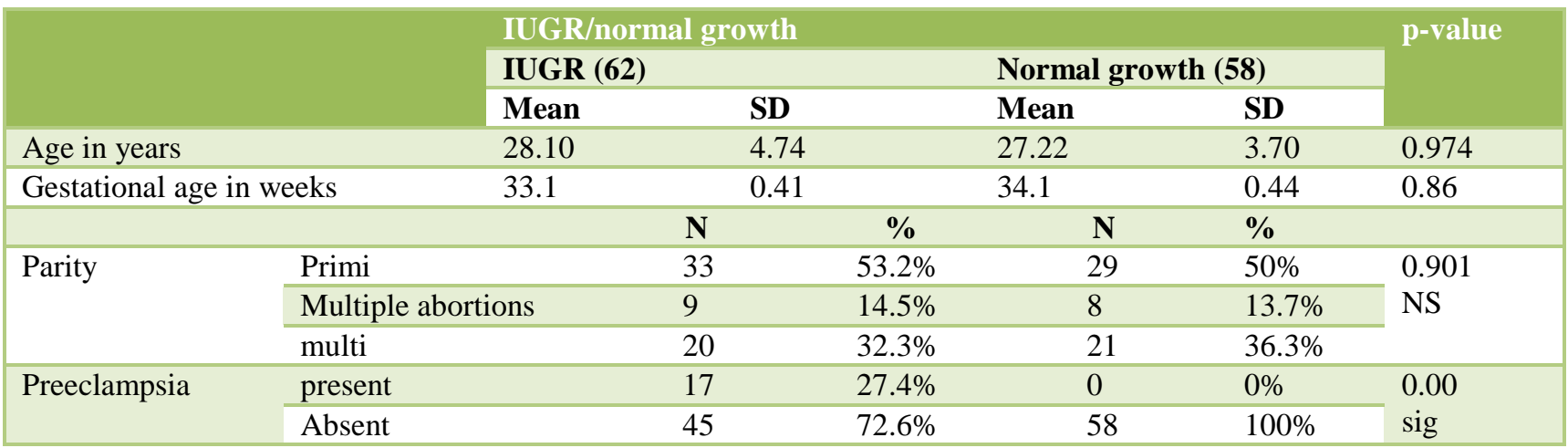

Chi Square test, $\mathrm{p}$ value $<0.05$ is significant. 


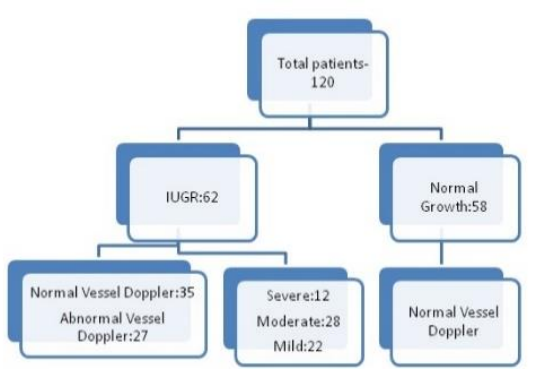

Figure 1: Flow chart depicting the study design.
All the babies with normal growth had normal conventional vessel Doppler. Among the babies with IUGR, twenty-seven had abnormal vessel doppler (defined as raised umbilical artery indices, absent or reversed end diastolic flow) while thirty-five had normal vessel doppler.

Myocardial tissue doppler was performed on all these patients and its efficacy in detecting cardiac dysfunction compared with that of conventional vessel doppler.

Table 2: Myocardial tissue Doppler parameters among IUGR and normal growth babies as a whole group.

\begin{tabular}{|c|c|c|c|c|c|}
\hline & & growth & & & p-value \\
\hline & IUGR & & Norm: & J-58) & \\
\hline & Mean & SD & Mean & SD & \\
\hline IV-E' & 0.038 & 0.01 & 0.041 & 0.01 & $0.17 \mathrm{NS}$ \\
\hline IV-A' & 0.048 & 0.011 & 0.050 & .014 & $0.28 \mathrm{NS}$ \\
\hline IV-E'/A' & 0.82 & 0.31 & 0.87 & 0.31 & $0.39 \mathrm{NS}$ \\
\hline IV-MPI' & 0.62 & 0.09 & 0.61 & 0.10 & $0.79 \mathrm{NS}$ \\
\hline LV-E' & 0.05 & 0.03 & 0.05 & 0.01 & $0.29 \mathrm{NS}$ \\
\hline LV-A' & 0.06 & 0.02 & 0.07 & 0.02 & $0.13 \mathrm{NS}$ \\
\hline LV-E'/A' & 0.84 & 0.35 & 0.76 & 0.21 & $0.11 \mathrm{NS}$ \\
\hline LV-MPI' & 0.63 & 0.13 & 0.65 & 0.11 & $0.55 \mathrm{NS}$ \\
\hline RV-E' & 0.07 & 0.008 & 0.06 & 0.01 & $0.34 \mathrm{NS}$ \\
\hline RV-A' & 0.09 & 0.023 & 0.10 & 0.026 & 0.03 Sig \\
\hline RV-E'/A' & 0.62 & 0.19 & 0.62 & 0.25 & $0.98 \mathrm{NS}$ \\
\hline RV-MPI' & 0.62 & 0.16 & 0.65 & 0.11 & $0.27 \mathrm{NS}$ \\
\hline
\end{tabular}

Table 3: Comparison of myocardial tissue doppler parameters in severe IUGR.

\begin{tabular}{|c|c|c|c|c|c|}
\hline & \multicolumn{2}{|c|}{ Severe IUGR (N-12) } & \multicolumn{2}{|c|}{ Normal (N-58) } & \multirow{2}{*}{ p-value } \\
\hline & Mean & SD & Mean & SD & \\
\hline IV-E' & 0.03 & 0.005 & 0.04 & 0.11 & $0.12 \mathrm{NS}$ \\
\hline IV-A' & 0.45 & 0.012 & 0.05 & 0.014 & $0.39 \mathrm{NS}$ \\
\hline IV-E'/A' & 0.82 & 0.31 & 0.85 & 0.31 & $0.71 \mathrm{NS}$ \\
\hline IV-MPI' & 0.61 & 0.10 & 0.63 & 0.09 & $0.49 \mathrm{NS}$ \\
\hline LV-E' & 0.04 & 0.007 & 0.05 & 0.01 & $0.01 \mathrm{Sig}$ \\
\hline LV-A' & 0.06 & 0.02 & 0.07 & 0.02 & $0.30 \mathrm{NS}$ \\
\hline LV-E'/A' & 0.75 & 0.34 & 0.76 & 0.23 & $0.97 \mathrm{NS}$ \\
\hline LV-MPI' & 0.56 & 0.20 & 0.65 & 0.11 & $0.16 \mathrm{NS}$ \\
\hline RV-E' & 0.06 & 0.001 & 0.06 & 0.016 & $0.84 \mathrm{NS}$ \\
\hline RV-A' & 0.09 & 0.024 & 0.10 & 0.27 & $0.21 \mathrm{NS}$ \\
\hline RV-E'/A' & 0.59 & 0.15 & 0.61 & 0.26 & $0.83 \mathrm{NS}$ \\
\hline RV-MPI' & 0.56 & 0.17 & 0.66 & 0.13 & $0.02 \mathrm{Sig}$ \\
\hline
\end{tabular}

Test used: Independent t test, p value $<0.05$ considered significant. E', A' in m/sec, E'/A' and MPI' are ratios.

The demographic characteristics of both these groups show no significant difference statistically (Table 1). The average gestational age at which the test was conducted was similar between the two groups hence gestational age as a confounding factor was ruled out. The Myocardial tissue doppler parameters of the two groups of IUGR and normal growth babies were compared using the independent t-test (Table 2). All the parameters of IUGR babies were found to be lower than the ones with normal growth. This however was found statistically significant only for the right ventricle A'. Atrial contraction velocity at the level of right ventricle is hence lower in IUGR babies indicating diastolic dysfunction in them. 
Table 4: Myocardial tissue doppler in IUGR babies with abnormal vessel doppler.

\begin{tabular}{|c|c|c|c|c|c|}
\hline & & & & & \\
\hline & Abnor & v-27) & Norm: & 58) & p-value \\
\hline & Mean & SD & Mean & SD & \\
\hline IV-E' & 0.037 & 0.009 & 0.040 & 0.011 & $0.13 \mathrm{NS}$ \\
\hline IV-A' & 0.04 & 0.13 & 0.05 & 0.014 & $0.50 \mathrm{NS}$ \\
\hline IV-E'/A' & 0.79 & 0.37 & 0.87 & 0.30 & $0.31 \mathrm{NS}$ \\
\hline IV-MPI' & 0.60 & 0.10 & 0.61 & 0.10 & $0.66 \mathrm{NS}$ \\
\hline LV-E' & 0.053 & 0.017 & 0.051 & 0.012 & $0.71 \mathrm{NS}$ \\
\hline LV-A' & 0.06 & 0.026 & 0.07 & 0.021 & $0.61 \mathrm{NS}$ \\
\hline LV-E'/A' & 0.76 & 0.37 & 0.75 & 0.21 & $0.86 \mathrm{NS}$ \\
\hline LV-MPI' & 0.62 & 0.17 & 0.65 & 0.11 & $0.47 \mathrm{NS}$ \\
\hline RV-E' & 0.063 & 0.011 & 0.062 & 0.01 & $0.77 \mathrm{NS}$ \\
\hline RV-A' & 0.09 & 0.02 & 0.10 & 0.02 & $0.05 \mathrm{Sig}$ \\
\hline RV-E'/A' & 0.64 & 0.15 & 0.62 & 0.26 & $0.73 \mathrm{NS}$ \\
\hline RV-MPI' & 0.58 & 0.14 & 0.65 & 0.12 & $0.019 \mathrm{Siq}$ \\
\hline
\end{tabular}

Test used: Independent t test, $\mathrm{p}$ value $<0.05$ considered significant. E', A' in m/sec, E'/A' and MPI' are ratios.

On comparing the parameters between babies with severe IUGR and normal growth babies, all were found lesser than the normal growth babies (Table 3). Statistically significant however was another right ventricular parameter, the MPI'. This indicates prolongation of ejection time of the right ventricle. The comparison when made between mild and moderate IUGR and normal growth babies showed reduced parameters in them too but none statistically significant.

When Myocardial tissue doppler parameters were compared between IUGR babies with abnormal vessel doppler and babies with normal growth, Right ventricular
A' and MPI' were found significantly lower indicating these parameters were affected especially in IUGR babies with abnormal vessel doppler (Table 4).

All the babies taken for the study were followed upto 7 days post-delivery. Twenty six IUGR babies required prolonged NICU admission among which fifteen had severe complications of respiratory distress requiring ventilator care. Other adverse neonatal outcomes like hypoglycemia and cardiomegaly were not found to be in sufficient number among the IUGR babies. There were three mortalities. Among the babies with normal growth, no adverse outcome was seen.

Table 5: Myocardial tissue parameters among IUGR babies with morbidities.

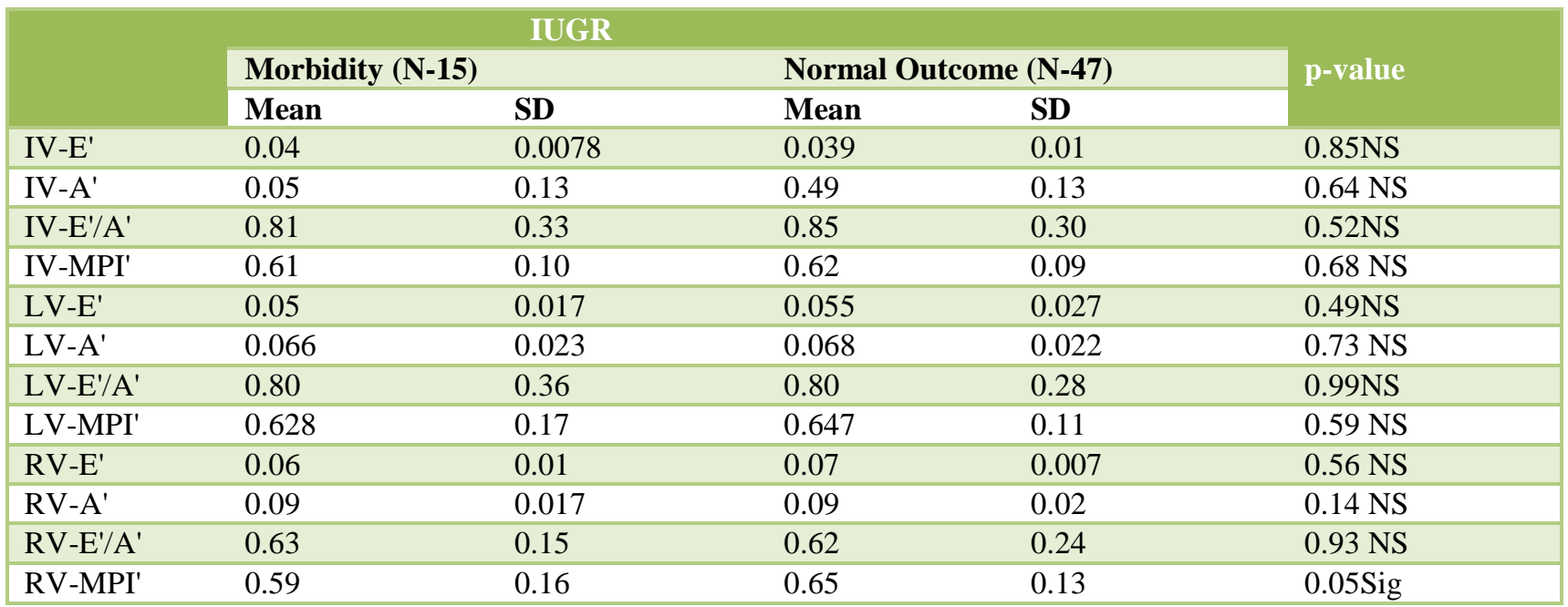

Test used: Independent t test, $\mathrm{p}$ value $<0.05$ considered significant. E', A' in m/sec, E'/A' and MPI' are ratios. Values in $\mathrm{m} / \mathrm{sec}$. 


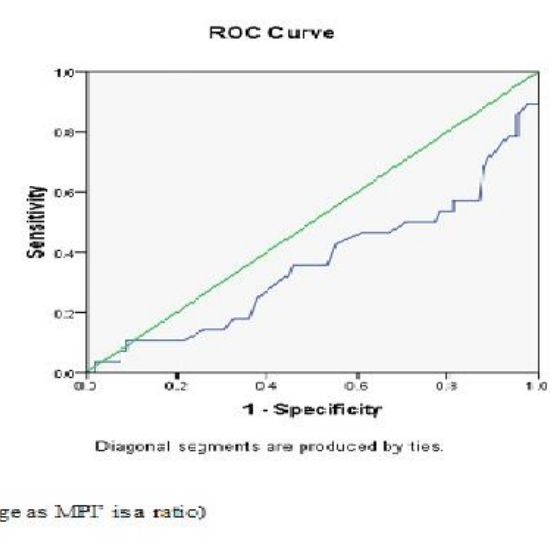

Figure 2: Sensitivity curve of right ventricular myocardial performance index in predicting adverse neonatal outcomes.

On comparing myocardial tissue doppler among the IUGR babies with adverse and IUGR babies with normal outcomes, the right ventricle MPI' was significantly lesser in the former (Table 5). This probably indicates the presence of right ventricular dysfunction in IUGR babies who develop adverse neonatal outcomes. On comparing and contrasting all IUGR babies and after their classification based on severity and vessel doppler and babies with normal growth, all myocardial tissue doppler parameters were found to be lower in the former. This difference was statistically significant consistently only for right ventricular tissue doppler MPI'. On comparison among the IUGR babies based on neonatal outcomes, the difference persisted. Hence, among all the variables, the Right ventricular MPI' was significantly affected and could act as a marker of cardiac dysfunction and adverse neonatal outcome in IUGR.

On preparing a correlation curve of right MPI' with neonatal outcomes, a negative correlation of was found (Figure 2). Lower the MPI', worse is the outcome of the baby. However the sensitivity as per the curve obtained is only $40 \%$ at a cut off value of 0.65 . Hence this value is likely to miss a lot of patients with adverse neonatal outcomes. Among the Twenty seven babies with IUGR and abnormal vessel Doppler, nineteen had values less than the defined cut off values as per the sensitivity curve. Out of these, eleven babies had adverse neonatal outcomes. When the same cut off was applied to IUGR babies with normal outcomes, there was still significant number of babies with abnormal values unlike Vessel Doppler which remained normal for these babies. Hence conventional vessel doppler was more sensitive than myocardial tissue doppler in accurately predicting babies with adverse neonatal outcomes.

\section{DISCUSSION}

It was a prospective observational study conducted to assess foetal cardiac dysfunction and perinatal outcome in IUGR with the help of myocardial tissue doppler. One hundred and twenty patients were taken among which sixty two were IUGR and fifty eight were foetuses with normal growth.

Myocardial tissue doppler was used for the study which uses the high amplitude and low frequency signals generated by the myocardial tissue while movement during the cardiac cycle giving an impartial view of the actual functioning of the different ventricles of the heart without being biased by the load conditions. This can enable us to identify if there is actual cardiac dysfunction or just altered functioning as a compensation to tide over unfavorable circulatory changes.

On comparison of the myocardial tissue doppler parameters in all the babies with IUGR and babies with normal growth, it was found that all the variables were lower in the former. This is suggestive of an overall reduction in the level of effective cardiac function in babies with IUGR. The parameter significantly reduced was Right ventricular A' which is dependent on the force of atrial contraction. With increasing gestational age the dependence of ventricular filling on the atrial contraction wave reduces. The finding of the study shows a persistence of the same in IUGR babies. It also shows that the right atrium is the first area to be affected with the increasing hypoxia of the placental insufficiency. In foetal life it is the right side of the heart which plays the dominant role in the circulation of blood. As a result this is the area to be more in requirement of oxygen and nutrients and also more susceptible for hypoxia and ischemia. This therefore explains the observation of right sided parameters to be abnormal with IUGR.

Like all IUGR babies combined, the parameters were all lower than the normal growth babies when compared separately for mild, moderate and severe IUGR. However, while in mild and moderately affected IUGR babies the difference was not statistically significant, in severely affected IUGR babies the right MPI' was significantly affected.

In the present study 35 IUGR babies were found to have normal vessel Doppler. Four of these had adverse neonatal outcomes. In the present study, it was found the Myocardial tissue Doppler parameters were not significantly different in the IUGR babies with normal vessel Doppler than the babies with normal growth. The babies with abnormal vessel doppler on the other hand showed significant reduction in Right ventricle $A^{\prime}$ and MPI'. This essentially shows that all abnormalities of myocardial tissue doppler seen in IUGR are only confined to the ones with abnormal vessel doppler. Hence conventional vessel doppler is as efficacious in detecting the babies with cardiac dysfunction.

Despite indicating the presence of cardiac dysfunction in IUGR babies, the myocardial tissue doppler parameters fared poorly in sensitivity and specificity in predicting the babies with increased chances of developing adverse 
neonatal outcomes. On account of its still being in the research phase, cut off levels as to what is defined as abnormal tissue doppler are not present. To enable looking for the level above which adverse neonatal outcome could be predicted, ROC curves were prepared for assessing the sensitivity of tissue doppler in predicting adverse neonatal outcomes. Using the cutoff as obtained by these curves to define normal and abnormal tissue doppler, not only do the curves in themselves show a poor sensitivity of $40 \%$ only for Right ventricle MPI', but also these values tag lot of IUGR babies with normal outcomes as having abnormal tissue doppler.

Undoubtedly, the babies with serious adverse outcomes seen in our study were all found to have abnormal Myocardial tissue doppler values, these were also detected as easily by vessel doppler. On the other hand myocardial tissue doppler showed an unacceptable number of abnormal values both in IUGR babies with normal outcome and normal vessel doppler. Myocardial tissue doppler has hence high numbers of false positives and low sensitivity in babies with IUGR.

There were as many as 15 babies with adverse neonatal outcomes of mainly respiratory distress and birth asphyxia. Comparable number of babies in this group had both abnormal Myocardial and conventional vessel doppler. The babies with adverse neonatal outcomes also conformed to the findings of IUGR babies with abnormal vessel doppler in having lower right ventricle MPI' in comparison to IUGR babies with normal outcomes. This shows good reliability of the technique in predicting adverse perinatal outcome in IUGR babies.

Of note however is the presence of a number of IUGR babies with normal neonatal outcome who still had abnormal myocardial tissue doppler. The Right ventricular MPI' has been found to have low sensitivity on statistical analysis in this study and this could be a reflection of the same. However we must not forget the long term effects of IUGR on cardiac function. This dysfunction as seen on myocardial tissue doppler in the IUGR babies who had normal perinatal outcome may be suggestive of cardiovascular problems in later life. But as the babies were not followed up for a long period of time this cannot be said to be definite.

In terms of specificity, myocardial tissue doppler still remained far behind conventional vessel doppler in finding lot of abnormal values also among babies with normal growth with no abnormal conventional vessel doppler or neonatal outcomes. Hence, if used as a predictive tool for adverse neonatal outcome, it can lead to undue anxiety or unnecessary interventions. Even though myocardial tissue doppler had a low sensitivity in predicting adverse perinatal outcome, it did indicate cardiac dysfunction in IUGR. Further research is hence needed with a larger sample size to further determine its usefulness. Dating forms an important consideration in the diagnosis of IUGR. In our data, most of the patients had excellent or good dating, so it can be reliably said that no patient was falsely categorized. All measurements were made on the same machine and were carried out by the same trained person. Hence the chances of interobserver variations and the problems of expertise and knowledge were nullified.

A major limitation of this study is that not many very severe IUGR babies (birth weight $<1 \mathrm{~kg}$ ) could be included. This was because many of these cases were unbooked and referred with foetal compromise necessitating immediate delivery. Another limitation is that Troponin $\mathrm{T}$ levels of these babies could not be done to correlate presence of deranged Myocardial Doppler findings with actual myocardial damage.

It can be argued that with increasing gestational age there is an increase in the volume and size of the cardiac tissue which can affect the findings of cardiac tissue function. This has been offset by taking nearly equal number of both IUGR and normal growth foetuses around the same gestational age. In a study by Chan et al, with increasing gestational age, the E' was found to increase progressively. ${ }^{10}$ The A' was also found to increase with gestation but the magnitude was smaller. In the present study, no such correlation was found. The myocardial velocities were much the same for foetuses at all gestational ages in both the groups. A possible reason for the same is that the Chan study took foetuses between 1937 weeks while in the present study all foetuses are in the third trimester.

A major limitation of this study is that not many very severe IUGR babies (birth weight $<1 \mathrm{~kg}$ ) could be included. This probably explains the observation of right ventricular A' only showing significant difference when all IUGR babies were taken together. As severity of IUGR progressed, the decrease in the right ventricle A' has probably been compensated with mechanisms of circulatory redistribution. As a result even though parameters are smaller, babies with mild and moderate IUGR do not show much difference from the normal growth babies. As the process of insufficiency worsens beyond the realm of compensation, the cardiac function worsens which has been observed with a decrease of the Right MPI', a marker of global cardiac function. As very severe IUGR babies could not be taken for the study whether the dysfunction spreads to the left ventricle and interventricular septum was not seen. A similar study was undertaken by Naujorks et al where the results obtained were comparable to the present study. ${ }^{6}$

A paradoxical finding in the present study which is not in accordance with the present literature is the finding of lower MPI' in IUGR babies in comparison to normal babies. All other studies show a higher value in IUGR babies explained by decreased stiffness of myocardial tissue in normal growth babies not seen in IUGR babies with increasing gestational age. This may be explained by the difference in genetic and ethnic factors owing to a 
different population. Another reason could be that the MPI' being an indicator of global cardiac function, includes three components of Isovolumetric contraction and relaxation as well as ejection time ,the observation of lower values could be due to derangement of any of them. Dysfunction could lead to a decreased contraction time and relaxation time or a prolonged ejection time. As the hemodynamic changes become more serious, due to the effect of saturation of the adaptive mechanisms of myocardial tissue ultimately the finding of increased MPI' in IUGR babies may develop as seen in other studies which took more of very severe IUGR babies.

The present study was undertaken to see if the upcoming technique of myocardial tissue doppler which already has proved its mettle in adults and children could be applied successfully in foetuses as well. While comparing its use in IUGR babies and normal growth babies, significant difference was indeed found in the right ventricle parameters. Right ventricle being the dominant ventricle in foetal life is obviously the first cardiac area to show the changes of IUGR. But trying to correlate this finding with conventional vessel doppler and perinatal outcome did not yield very good results. Not only the myocardial tissue doppler parameters show low sensitivity in detecting adverse outcomes it also had low specificity and was no better than conventional vessel doppler for the same.

\section{CONCLUSION}

We conclude that myocardial tissue doppler shows right ventricular dysfunction in IUGR. this change was more significant in babies with severe growth restriction, abnormal vessel doppler and adverse perinatal outcomes. myocardial tissue doppler is however not a sensitive indicator of adverse perinatal outcome in IUGR babies. Hence it is only a research tool and not useful in the clinical management of IUGR babies where conventional vessel doppler is more useful.

\section{ACKNOWLEDGEMENTS}

Authors would like to thank Dr. Lavanya Rai, Dr. Jyoti Shetty, Dr. Sapna Amin, Dr. Pratap Kumar and Dr. Muralidhar V. Pai for their valuable help and guidance in conducting this study.

\section{Funding: No funding sources} Conflict of interest: None declared

Ethical approval: The study was approved by the Institutional Ethics Committee of Kasturba Hospital, Manipal, India. Approval No IEC 219/2011

\section{REFERENCES}

1. Mäkikallio K, Vuolteenaho O, Jouppila P, Räsänen J. Association of severe placental insufficiency and systemic venous pressure rise in the fetus with increased neonatal cardiac troponin $\mathrm{T}$ levels. Am J Obstet Gynecol. 2000;183:726-31.

2. Acharya G, Räsänen J, Mäkikallio K, Erkinaro T, Kavasmaa T, Haapsamo M, Mertens L, Huhta JC. Metabolic acidosis decreases foetal myocardial isovolumic velocities in a chronic sheep model of increased placental vascular resistance. Am J Physiol Heart Circ Physiol. 2008; 294:498-504.

3. Crispi F, Hernandez-Andrade E, Pelsers MM, Plasencia W, Benavides-Serralde JA, Eixarch E, et al. Dysfunction and cell damage across clinical stages of severity in growth-restricted fetuses. Am J Obstet Gynecol. 2008;199:254.

4. Mäkikallio K, Vuolteenaho $\mathrm{O}$, Jouppila $\mathrm{P}$, Räsänen J. Ultrasonographic and biochemical markers of human foetal cardiac dysfunction in placental insufficiency. Circulation. 2002;105:58-63.

5. Bahtiyar MO, Copel JA. Cardiac changes in the intrauterine growth-restricted fetus. Semin Perinatol. 2008;32:190-3.

6. Naujorks AA, Zielinsky P, Beltrame PA, Castagna RC, Petracco R, Busato A, Nicoloso AL, Piccoli A, Manica JL. Myocardial tissue doppler assessment of diastolic function in the growth-restricted fetus. Ultrasound Obstet Gynecol. 2009;34:68-73.

7. Comas M, Crispi F, Cruz-Martinez R. Usefulness of myocardial tissue Doppler versus conventional echocardiography in the evaluation of cardiac dysfunction in early-onset intrauterine growth restriction. Am J Obstet Gynecol. 2010;203:451-7.

8. Comas M, Crispi F, Cruz-Martinez R. Tissue doppler echocardiographic markers of cardiac dysfunction in small-for-gestational age fetuses. Am J Obstet Gynecol. 2011; 205:571-6.

9. Doppler Ultrasound in obstetrics and gynecology. In: Ott MWJ eds. Doppler ultrasound in the diagnosis and management of IUGR. 2nd ed. New York. Springer; 2005:281-93.

10. Chan LY, Fok WY, Wong JT, Yu CM, Leung TN, Lau TK. Reference charts of gestation-specific tissue doppler imaging indices of systolic and diastolic functions in the normal foetal heart. Am Heart J. 2005; 150:750-5.

Cite this article as: Basu B, Shetty R, Gupta K. Assessment of foetal cardiac function by myocardial tissue doppler in foetal growth restriction. Int $\mathbf{J}$ Reprod Contracept Obstet Gynecol 2017;6:1045-51. 